In defence of agent-based virtue ethics

\author{
Liezl van Zyl \\ Department of Philosophy and Religious Studies \\ University of Waikato \\ New Zealand \\ liezl@waikato.ac.nz
}

\begin{abstract}
:
In 'Against agent-based virtue ethics' (2004) Michael Brady rejects agent-based virtue ethics on the grounds that it fails to capture the commonsense distinction between an agent's doing the right thing, and her doing it for the right reason. In his view, the failure to account for this distinction has paradoxical results, making it unable to explain why an agent has a duty to perform a given action. I argue that Brady's objection relies on the assumption that an agent-based account is committed to defining obligations in terms of actual motives. If we reject this view, and instead provide a version of agent-basing that determines obligations in terms of the motives of the hypothetical virtuous agent, the paradox disappears.
\end{abstract}

Word count: 5795 


\section{In defence of agent-based virtue ethics}

There is striking agreement among consequentialists that the motive of an action cannot affect its rightness. For example, J.S. Mill insists that we must distinguish 'the very meaning of a standard of morals,' which provides 'the rule of action,' from the motive of the action: 'He who saves a fellow creature from drowning does what is morally right, whether his motive be duty or the hope of being paid for his trouble; he who betrays the friend that trusts him is guilty of a crime, even if his object be to serve another friend to whom he is under greater obligations. ${ }^{1}$ Similarly, most deontologists agree that the motive of an act cannot affect its rightness. Kant distinguishes between an agent's 'acting in accordance with duty' and 'acting from the motive of duty,' illustrating this with the example of a grocer who does not overcharge his customers but only for reasons of prudence. For Kant, the act conforms to his duty and is therefore right; but because it is not done from duty it has no moral worth. ${ }^{2}$

In contrast to this commonly accepted view, Michael Slote defends an agent-based account of virtue ethics which 'treats the moral or ethical status of acts as entirely derivative from independent aretaic (as opposed to deontic) ethical characterisations of motives, character traits, or individuals. ${ }^{3}$ On this account, acts have no independent moral status but are made right because they are done from virtuous motives. The emphasis on motivation is fundamental, insofar as it claims that certain forms of motivation are intuitively good and approvable in themselves, quite apart from their consequences or the possibility of grounding them in rules or principles. While it is hard to find a precise formulation of Slote's criterion of right action, the following seems a fair statement of the view:

\footnotetext{
${ }^{1}$ J.S. Mill, Utilitarianism, chap. 2, par. 19, ed. George Sher (Indianapolis: Hackett, 1979), pp. 17-18. ${ }^{2}$ Immanuel Kant, Groundwork of the Metaphysics of Morals, trans. H.J. Paton (New York: Harper \& Row, 1964), p. 65.

${ }^{3}$ Michael Slote, Morals from Motives (Oxford University Press, 2001), p. 4. See also his 'Agent-based virtue ethics', Midwest Studies in Philosophy vol. 20, Moral Concepts, eds. Peter A. French, Theodore E. Uehling, Jr., and Howard K. Wettstein. (Notre Dame, Ind.: University of Notre Dame Press, 1996), pp. 83-101.
} 
An action is right if and only if it exhibits or expresses a virtuous motive, or at least does not exhibit or express a vicious motive.

Slote distinguishes theories that are radically agent-based in this sense from accounts that are merely agent-focused, most notably Aristotelian versions such as those provided by Rosalind Hursthouse ${ }^{4}$ and Linda Zagzebski. ${ }^{5}$ Aristotelians do focus more on the evaluation of agents and character traits than on the evaluation of acts.

However, they allow that nonvirtuous individuals can perform good or virtuous acts under the direction of others. The virtuous individual is characterised as someone who sees or perceives what is good or fine or right to do in any given situation, ${ }^{6}$ which, as Slote points out, implies that the virtuous individual does what is noble or virtuous because it is the noble thing to do, rather than it being the case, as Slote would have it, that what is noble to do has this status simply because the virtuous individual actually will choose or has chosen it.

Slote has been led to agent-based virtue ethics out of recognition of the circularity objection that confronts Aristotelian accounts of morality. ${ }^{7}$ In his view, if the rightness of actions depends on hypothetical facts about the virtuous person, then we cannot, on pain of circularity, say that virtue consists in part in a disposition to see and do what is right and noble. Instead, we will need some other account of what virtue consists in. One possibility, which Slote briefly considers, is to define the virtues as those character traits necessary for human flourishing or eudaimonia. ${ }^{8}$ According to Slote, the difficulty for this approach is to provide a non-circular account of eudaimonia, one that does not make reference to right action.

Agent-based virtue ethics avoids the circularity problem by defining right action in terms of virtuous motive, and then taking virtue as fundamental, as intrinsically and

\footnotetext{
${ }^{4}$ On Virtue Ethics (Oxford University Press, 1999). Hursthouse proposes that 'An action is right iff it is what a virtuous agent would characteristically do in the circumstances', p. 18.

${ }^{5}$ Virtues of the Mind (Cambridge University Press, 1996). Zagzebski holds that 'A right act is an act that a virtuous person might do in certain circumstances', p. 233.

${ }^{6}$ See Aristotle's Nicomachean Ethics, trans. David Ross. (Oxford and New York: Oxford University Press, 1998), 11. 1105a 17ff.

${ }^{7}$ Slote (2001), pp. 5-6. Slote is not the only one to make this objection. See Thomas Hurka, Virtue, Vice, and Value, (New York: Oxford University Press, 2001), pp. 228ff, as well as Ramon Das (2003)

'Virtue ethics and right action, Australasian Journal of Philosophy 81 (3), pp. 330-334.

${ }^{8}$ See, for example, the account provided by Hursthouse (1999).
} 
independently good. However, this makes it vulnerable to a different kind of objection commonly levelled against agent-based accounts, namely that it is incapable of capturing or explaining the commonsense distinction between an agent's doing the right thing, and her doing it for the right (or wrong) reason. If an agent's motives are good, agent-based virtue ethics would seem committed to claiming that the action is right; whereas if the motives are bad, the theory would claim that the action is wrong. My aim in this paper is to respond to Michael Brady's version of this objection, ${ }^{9}$ according to which the failure by agent-based virtue ethics ${ }^{10}$ to provide a criterion of right action that is independent of the agent's motives (and hence to capture the commonsense distinction between acting rightly and acting rightly for the right reason), makes it unable to explain why a badly motivated agent has a duty or obligation to perform a specific action.

I will argue that this objection relies on a view of agent-based virtue ethics as committed to determining moral obligations (as opposed to assessing actions) on the basis of the agent's actual motives for acting, rather than the motives of a hypothetical virtuous agent. Brady takes the main difference between agent-based and Aristotelian virtue ethics to be that the latter makes reference to the motives of the hypothetical virtuous agent, whereas Slote furnishes his account of morality solely in terms of the motives from which the action proceeds. However, Slote himself never draws attention to this presumed difference, and the only reason he gives for rejecting Aristotelian accounts is the circularity objection mentioned above. To be fair, and as I will discuss in more detail below, much of what Slote says on this point is ambiguous. He clearly provides an account of right action in terms of the agent's actual motives, but when it comes to discussing action guidance, he often (if not consistently) employs a hypothetical-agent account. I will argue that Brady's objection can be met by a revised version of agent-based virtue ethics, one that gives a hypothetical-agent

\footnotetext{
${ }^{9}$ Brady (2004), 'Against agent-based virtue ethics', Philosophical Papers 33(1), pp. 1-10. For different versions of the same objection see Scott Gelfand, (2000) 'Hypothetical agent-based virtue ethics', Southwest Philosophy Review 17 (1), pp. 85-94; Christine Swanton (2001), A virtue ethical account of right action, Ethics 112 (1), pp. 32-52; Dan Jacobson, (2002), 'An unsolved problem for Slote's agentbased virtue ethics', Philosophical Studies 111 (1), pp. 53-67; and Das (2003), pp. 324-327.

${ }^{10}$ Although Brady distinguishes between Slote's account and Aristotelian accounts in much the same way that Slote does, he refers to both accounts as 'agent-based.' For the sake of clarity, I will in what follows use the term 'agent-based virtue ethics' to refer to accounts that ties rightness to the actual motives of the agent, while taking virtue as fundamental. I will use the term 'Aristotelian virtue ethics' to refer to accounts that tie rightness to the hypothetical motives of virtuous people, while defining virtue in terms of eudaimonia.
} 
account of action guidance, while retaining an account of action assessment that ties rightness to the agent's motive for acting. This will enable us to say that an agent made the right decision in choosing to perform a certain action, but because he was not well-motivated the act in question is morally wrong. The main problem with Slote's account, in my view, is that he does not explicitly develop or defend this method of determining obligations, despite the fact that it is required to make sense of his discussion of the distinction between doing the right thing and doing the right thing for the right reason.

\section{I}

Slote is aware that agent-based virtue ethics does not capture the distinction between acting rightly and acting rightly for the right reasons, but does not think that intuition should be taken as the final arbiter in these matters. In an effort to explain away the significance of this distinction, he considers Sidgwick's example of the malicious prosecutor, 'who does his duty by trying to convict a defendant, but who is motivated by malice rather than by a sense of public duty. ${ }^{11}$ Some critics object that agentbasing is committed to judging as wrong the intuitively right act in this case. ${ }^{12}$ By saying that the prosecutor acts wrongly by prosecuting from malice, we seem to imply that the agent should not have prosecuted, or that he did not have a duty or obligation to do so, regardless of his motives. And this is clearly an implausible result. Foreseeing this objection, Slote agrees that in this instance agent-basing will insist that the prosecutor acts wrongly. However, he argues that agent-basing can nevertheless allow that the prosecutor has a duty to prosecute, and that this allows it to make the distinction between 'doing one's duty for the right reasons and thus acting rightly, on the one hand, and doing one's duty for the wrong reasons and thus acting wrongly.' 13

The important question is how such a duty or obligation can be understood in agentbased terms. In considering this question Slote notes that a failure to prosecute will also express a bad motive. He asks us to imagine that the prosecutor, 'horrified by his

\footnotetext{
${ }^{11}$ Slote (2001), pp. 13-14.

${ }^{12}$ See Das (2003), p. 326; Swanton (2001), p. 36.

${ }^{13}$ Slote (2001), p. 15.
} 
own malice... ends up not prosecuting. ${ }^{14}$ In Slote's view, this action too will come from an inner state that is morally criticisable, for one likely explanation of his failure will be a lack of concern for doing his job and playing the contributing social role that that involves. Thus, he concludes, agent-based virtue ethics can explain why the agent has a duty to prosecute.

Brady argues that this attempt at giving an agent-based account of moral obligations does not work. When Slote writes that it would be wrong for the agent not to prosecute, Brady (quite plausibly) understands him as saying that he has a duty to prosecute, since '(i) in the absence of countervailing reasons, failure to prosecute would express an intrinsically bad motive and would thus be wrong, and (ii) an agent has a duty to $\mathrm{X}$ if it would be wrong for him to do otherwise. ${ }^{, 15}$ A problem that appears at this point, according to Brady, is that Slote has contradicted a central tenet of agent-based virtue ethics, namely that the moral status of some action entirely depends upon the status of the agent's motives:

If this approach is to capture the notion that an agent can do his duty for the wrong reason ... it cannot maintain that an agent's duty depends entirely upon the status of the motives which are expressed by the agent's performing that action. Agent-based virtue ethics must claim, instead, that an agent's duties can be defined independently of such motives, i.e., in terms of the motives which would be expressed if he acted otherwise. ${ }^{16}$

This, Brady continues, lends agent-based virtue ethics an air of paradox:

[I]f Slote is right, and the prosecutor does indeed have a duty to prosecute, then his motives in prosecuting would seem to change what he has a duty to do. Thus if he has a duty to prosecute, because a failure to do so would express a bad motive, then his doing his duty from a malicious motive means that it would be wrong for him to prosecute, and thus means that he doesn't have a

\footnotetext{
${ }^{14}$ Slote (2001), p. 14.

${ }_{15}$ Brady (2004), pp. 5-6.

${ }^{16}$ Brady (2004), p. 6.
} 
duty to prosecute after all. Instead, given his malicious motive, our prosecutor has a duty not to prosecute. ${ }^{17}$

This leads Brady to conclude that, if Slote insists that the rightness or wrongness of an action depends upon the goodness of the motives expressed by that action, he will be unable to explain why the malicious prosecutor has a duty to prosecute, and thus be unable to explain how one can do one's duty but for the wrong reason.

\section{II}

Brady has identified a serious problem for Slote's agent-based ethics, namely that it is unclear from his discussion of the prosecutor case why the agent has a duty to prosecute, given his malicious motives. Slote assesses actions on the basis of the motives from which they proceed, but on what grounds could such an account determine obligations? In cases where the agent is well-motivated, it seems clear that she should perform that action that would allow her to express her good motives. But in cases where the agent is not well-motivated, a problem appears. In the prosecutor case, we have seen, Brady takes Slote as defining obligations in terms of the motives which would be expressed if the agent acted otherwise. The first problem Brady identifies in this regard is that this account of obligations conflicts with Slote's insistence that agent-based virtue ethics bases rightness on the motive from which the act proceeds. A second problem he identifies is that the use of such an account of obligations leads to paradoxical results. I will consider these two problems separately, beginning with the latter.

Brady is correct in claiming that the use of an account of obligation in terms of the motive that would be expressed if the agent acted otherwise leads to paradoxical results. In his discussion of the prosecutor case Slote seems both to be saying that (i) it would be wrong to prosecute from malice and that (ii) it would be wrong not to prosecute. If it is reasonable to infer from (ii) that the agent has an obligation to prosecute, then Slote has failed to explain why the prosecutor, given his malicious motives, nevertheless has a duty to prosecute. It is notable that in considering the

\footnotetext{
${ }^{17}$ Ibid.
} 
question, 'how can such a duty (or obligation) be understood in agent-based terms?' 18 Slote never mentions what the prosecutor ought to do, only what it would be wrong for him to do. So I think that this part of Brady's objection is entirely justified.

Turning now to the first part of his objection, let us assume that Brady is correct in claiming that Slote derives obligations from the motives that would be expressed if the agent acted otherwise. Does this make him guilty of violating a central tenet of agent-based virtue ethics (namely, that it bases rightness on the actual motives from which the act proceeds)? Certainly, the use of such an account of moral obligation is inconsistent with what Slote himself says in Chapter 2 of Morals from Motives, where he discusses the question of whether agent-basing is practical. Slote begins this chapter by considering an account of action guidance that is directly derived from his criterion of right action, and that can be formulated as follows:

$\mathrm{AG}_{\mathrm{am}}$ : One ought to perform the action that will exhibit or express a virtuous motive, or at least will not exhibit or express a vicious motive.

Slote distinguishes two senses in which a moral theory can be said to be practical. The first of these is that it can be used as a decision-making tool by an agent facing a moral dilemma, and the second is that it can be used by a philosopher or an adherent of that theory to determine the agent's obligation in any given case. Slote denies that agent-basing is practical in the first sense, on the grounds that 'the morally good person isn't guided by a theory or (agent-based) moral principle or even a sense of rightness as much as by a good heart that seeks to do good for and by people. ${ }^{19} \mathrm{He}$ still thinks, however, that a principle such as $A_{\mathrm{am}}$ can be used in the second sense mentioned above. One of the problems with an action-guiding principle such as $\mathrm{AG}_{\mathrm{am}}$, even if used in this limited sense, is the one discussed before, namely that it cannot explain why a badly-motivated agent nevertheless has an obligation to perform a certain action, and I agree with Brady that this is a serious problem for Slote.

I'm not convinced, however, that this is a fatal problem for agent-based virtue ethics. There seems to me no reason, in principle, why a moral theory must employ an

\footnotetext{
${ }^{18}$ Slote (2001), p. 14.

${ }^{19}$ Slote (2001), p. 42.
} 
action-guiding principle that exactly mirrors (or is derived from) its criterion of right action. Many moral theorists deny that action guidance and action assessment coincide in this way. ${ }^{20}$ The proponent of agent-basing could possibly employ a different criterion of action guidance, one that does not make reference to actual motives. Indeed, one way to make sense of Slote's claim that an agent who prosecutes from malice will be 'doing [his] duty for the wrong reasons and thus acting wrongly, ${ }^{21}$ is to see action guidance and action assessment as coming apart in exactly this way, that is, as implying that the agent (or anyone else in his position) should prosecute (for this will express concern for doing his job and playing a contributing social role), but that if he then goes on to prosecute from malice (and not from a concern for doing his job, etc.) his act would be morally wrong. It is neither paradoxical nor inconsistent to say that the agent in this case does what he ought to do, or what he has a duty or obligation to do, but nevertheless acts wrongly because he acts from malice (that is, because the motives he ought to express differ from the motives he actually does express).

\section{III}

If we accept the claim that action guidance and action assessment can come apart, then the question arises as to how the supporter of agent-based virtue ethics can determine an agent's duty, if not on the basis of actual motives. The possibility mentioned by Brady, namely that duties can be defined in terms of the motives that would be expressed if the agent acted otherwise, and which he argues (and I agree) leads to paradoxical results, is certainly not the only one. Another possibility, and one that I will explore in more detail in what follows, is to base duties on the motives of the hypothetical virtuous person. In this paper I will focus on outlining my proposal as

\footnotetext{
${ }^{20}$ For example, a number of theorists have argued that utilitarianism should be construed only as a criterion of rightness and that it can allow and even encourage the use of some other decision procedure or method of determining what an agent's moral obligation consists of. See Peter Railton, (1984) Alienation, consequentialism, and the demands of morality. Philosophy and Public Affairs 13, pp. 152153; R.M. Hare, Moral Thinking: Its levels, Method, and Point (Oxford: Oxford University Press, 1981) chaps. 2 \& 3. Hursthouse similarly argues that action guidance and action assessment can come apart. She explains the distinction as follows: When I am seeking action guidance, I am asking, 'What should I do in this situation?' or 'What would be the right decision?' A person advising me might say, 'You ought to do $\mathrm{x}$ ' or ' $\mathrm{x}$ would be the right thing to do.' To assess an act is to ask, 'Is $\mathrm{x}$ right (or good or virtuous)?', and to say that ' $\mathrm{x}$ is the right action' is to give it a tick of approval (1999), pp. 49-51.

${ }^{21}$ Slote (2001), p. 15.
} 
well as indicating its advantages, while for the most part disregarding what Slote himself says in this regard.

Briefly, what I propose is an agent-based virtue ethics that ties rightness to the agent's actual motives,
AA: An action is right if and only if it exhibits or expresses a virtuous motive, or at least does not exhibit or express a vicious motive

while using the following action-guiding principle:

\begin{abstract}
$\mathrm{AG}_{\mathrm{h}}$ : One ought to perform the action that a virtuous person would characteristically choose in the circumstances.
\end{abstract}

One of the advantages of a decision-making principle that defines obligations in terms of the motives of the hypothetical virtuous agent, is that obligations do not somehow change depending on the agent's motive, in the way that Brady argues the criterion employed by Slote does. It allows us to explain how it is possible for an agent to perform their duty but nevertheless act wrongly. In the case of the malicious prosecutor we could say, following $\mathrm{AG}_{\mathrm{h}}$, that the agent has a duty to prosecute, because this is what someone motivated by a concern for doing their job will do in these circumstances. However, if the agent then goes on to prosecute from malice, he will be performing his duty for the wrong reason, and therefore act wrongly. The advantage of this approach is that it allows us to assess the act as morally wrong without thereby implying that the agent should not have prosecuted. In this way it avoids Brady's paradox.

By way of illustration, consider the case of a man who impregnates a woman who is deeply in love with him. In such a case we might say that the right thing to do would be to marry her (or at least to support her in some other way), perhaps giving as a reason for our judgement that it is the decent thing to do, or that it will allow him to express virtuous motives. If, however, the man then goes on to marry the woman with the exclusive motive of securing a large inheritance, it would be inappropriate to say that he did the right thing despite acting from greed. His actions do not warrant a tick 
of approval, and we would quite justifiably be appalled at his behaviour. If he then protests that he did exactly what we advised him to do, we could explain that although he ought to have supported the woman, it is not sufficient to merely do what a virtuous would do (or would advise one to do). The reason why in most cases supporting someone is morally right is that it is typically motivated by virtue (such as love, decency, respectfulness). However, if a particular act of supporting someone is not well-motivated, then it is not morally right.

At this point one might want to object that the adoption of $\mathrm{AG}_{\mathrm{h}}$ is somewhat ad hoc, arising out of the need to respond to the objection levelled by Brady and others. To see how $\mathrm{AA}$ and $\mathrm{AG}_{\mathrm{h}}$ are connected, it is helpful to consider how someone subscribing to AA would go about deciding what to do. How will she choose between $x$ and $y$ ? Presumably, following AA, she should choose the act that will allow her to express virtuous motives (say, benevolence), but how does she know which action will allow her to do so? In most cases this will be obvious, so that the question of which action-guiding principle to follow does not even arise. However, in many cases it will not be obvious what to do, either because it is a complex case or because the agent is not (yet) fully benevolent (she may lack the necessary skills and knowledge). In such cases, examining her own motives and trying to act on whichever of these she perceives to be virtuous will not produce an act that is fully benevolent (that is, motivated by true benevolence). Arguably the most reliable way to express benevolence is to consider the ways in which truly benevolent people characteristically act: 'How do they manage to succeed in helping others?', 'How do they express their benevolence?', and 'What do they typically do in this kind of situation?'.

In most cases, this will allow the agent to express a virtuous motive and hence to act rightly. It does not follow, however, that adhering to the maxim, 'Do what a virtuous person would characteristically do in the circumstances' will necessarily issue in an act that is right, for the agent's true reason for acting might be to deceive others in thinking that she is virtuous. In such cases our revised agent-based account will assess 
the act as wrong, even though it will hold that the agent made the right decision (i.e., chose an act that would have allowed the agent to express a virtuous motive). ${ }^{22}$

We are now in a position to see how close this account comes to making the traditional distinction between doing the right thing and doing the right thing for the right reason. Consider again the case of the man who marries a pregnant woman, but who is motivated exclusively by a desire to secure an inheritance. In this case our revised agent-based account says that the agent ought to marry the woman (or that marrying her would be the right decision), but that if he does so for the wrong reason his act would be morally wrong. By contrast, traditional deontological and consequentialist approaches say that marrying her is the right act, but that if the agent does so from greed he would perform a right act for the wrong reason. Hence they make a distinction between right acts and praiseworthy (or well-motivated) acts, and although they agree with agent-based accounts that the praiseworthiness of an act depends on the agent's motives, their focus is on the first, that is, on providing an account of rightness in terms of consequences or principles. By contrast, the agentbased account proposed here distinguishes between making a right decision (on the grounds that it conforms to what virtuous agents characteristically do in similar circumstances) and performing a right (or praiseworthy) action, and its focus is on the latter.

\section{IV}

By way of conclusion I will briefly consider two possible objections one might have to the revised agent-based account. The first is that by incorporating a hypothetical principle of action guidance $\left(\mathrm{AG}_{\mathrm{h}}\right)$, while retaining a criterion of right action based on actual motives (AA), we end up with a 'hybrid' account of morality, and that this in effect means that we've failed to defend an agent-based morality. This objection is closely related to one mentioned earlier, namely that the revised account may seem somewhat ad hoc. In response, and in addition to what I said before in this regard, I

\footnotetext{
${ }^{22}$ It is worth noting that this account of rightness is not perfectionist in the way that Aristotelian versions are, insofar as it requires only that the action does not express or exhibit a vicious motive. This means that an agent who has certain shortcomings with regards to virtue, but who tries to do what virtuous agents characteristically do, will act rightly even if they fail to act from full virtue. As long as the action does not display vice (such as carelessness, insensitivity, or wilful ignorance), it will be morally right or acceptable.
} 
would simply deny that the account is in any way a 'hybrid.' Instead, it is firmly agent-based in that the focus remains on providing an account of right action in terms of the actual motives from which the act proceeds. $\mathrm{AG}_{\mathrm{h}}$ does not say anything about what makes an action right. It only provides a practical decision-making tool, advising that the best or most reliable way to go about being and becoming good people and acting well is for us to try to do what virtuous people characteristically do (which includes acting for the same reasons and in the same way that they characteristically do). As we have seen, emulating virtuous people does not necessarily result in a right act, for to act well we need to be motivated by virtue. To understand - on a more theoretical level - why the actions that virtuous people characteristically perform are right (and why superficial emulation will not do), we need to make reference to the motives from which they typically proceed, and this brings us back to an agent-based criterion of right action (AA). The revised account therefore remains agent-based, even if it uses a hypothetical-agent principle as a practical decision-making tool, in the sense that it 'treats the moral or ethical status of acts as entirely derivative from independent and fundamental aretaic (as opposed to deontic) ethical characterizations of motives, character traits, or individuals. ${ }^{23}$

Another concern one might have about adopting $\mathrm{AG}_{\mathrm{h}}$ is that it makes our account vulnerable to the same problems faced by hypothetical-agent accounts such as the one provided by Hursthouse. Brady discusses one of these problems. He notes that an Aristotelian (or hypothetical-agent) account appears to avoid the problems faced by agent-based accounts, for it can make the distinction between right acts and wellmotivated acts. It can allow that an agent does the right thing (on the grounds that it is what a virtuous person would do in the circumstances), while also saying that an agent who acts from an inferior motive does the right thing for the wrong reason. However, Brady goes on to argue, the shift from actual to hypothetical motives only appears to solve the problem. In order to allow for the possibility that an agent can do the right thing but for the wrong reason, hypothetical accounts deny that there is a necessary grounding relation between the badness of the motive actually expressed by an action

\footnotetext{
${ }^{23}$ Slote (2001), p. 5 .
} 
and the wrongness of that action. This raises the question: 'What makes an action wrong, if not the actual motives expressed in the action? ${ }^{24}$

I think Brady is correct in suggesting that Hursthouse relies on an unexplained concept of right action. One problem with this is that it makes her account vulnerable to the circularity objection mentioned at the beginning of this paper. Hursthouse specifies the virtuous person in terms of the virtues and then specifies these as the character traits required for eudaimonia. ${ }^{25}$ It is unclear, however, whether it is possible to explain eudaimonia in a non-circular way, that is, without making reference to right action. It should be clear by now that the revised agent-based account proposed here is not vulnerable to the same objection, for it uses the actions that virtuous agents typically perform only as a guide to decision-making. When it comes to explaining what makes an action morally right (that is, why the actions that virtuous persons characteristically perform are right), it does not make reference to eudaimonia. Instead, it says that what makes an act right is that it is motivated by virtue, and takes the virtues to be intuitively and fundamentally good.

I've tried to show that agent-based virtue ethics, at least in a revised form, is immune to the criticism most often levelled against it, namely that it does not provide a satisfactory account of action guidance. It also has certain advantages to Aristotelian virtue ethics, in that it avoids the circularity problem. However, it remains to be shown whether agent-based virtue ethics provides a stronger account of morality than deontology and consequentialism. I can only hint at one such advantage here, one that I consider to be significant, namely that agent-based virtue ethics is not vulnerable to moral luck in the same way or to the same extent that classical deontological and consequentialists theories are. A serious problem for consequentialm is that of consequential luck, namely that the moral status of an act depends, often to a large degree, on factors beyond the agent's control. This makes it implausible to describe acts as right or wrong based on their consequences, for these terms imply a level of responsibility or control. The problem of moral luck appears in a slightly different way for deontological theories. While immune to the problem of consequential luck, for deontologists the problem arises that one can do one's duty (or act in accordance

\footnotetext{
${ }^{24}$ Brady (2004), pp. 7-8.

${ }^{25}$ Hursthouse (1991), pp. 225-226.
} 
with duty) purely by accident or for reasons that are morally objectionable. In such cases Kantians would say that the agent failed to act for the sake of duty. However, as noted before, their emphasis is on acting rightly (or doing one's duty), rather than acting for the right reasons.

By providing a non-consequentialist account of right action, agent-based virtue ethics avoids the problem of consequential luck. An agent will be held responsible for the consequences of her action if they are the result of non-virtuous traits such as carelessness, wilful ignorance, or the like, but not if they are purely the result of bad luck. Slote hints at this advantage when he writes:

...motive is fundamentally at least relevant to the moral character of any action. For if we judge the actions of ourselves or others simply by their effects in the world, we end up unable to distinguish accidentally or ironically useful actions (or slips on banana peels) from actions that we actually morally admire and that are morally good and praiseworthy. ${ }^{26}$

In an agent-based morality, we have seen, an agent could make the right decision and do his or her duty for the wrong reasons (or for no reasons at all), and in this way there is an element of luck involved. However, it would deny that such an act can be described as morally right, for in an agent-based view an act is right only if it is praiseworthy, that is, motivated by virtue. Of course, it could be argued that agentbasing is vulnerable to a different kind of moral luck, what is often referred to as 'constitutive luck,' for character itself is at least partly the result of factors beyond the individual's control. I cannot address this problem here, except to note that once we give up the idea that agents are responsible, if not for their character and motives as such, then at least for the motives they choose to express in their actions, we will have to abandon the whole project of morality and the notion of moral agency, admitting, in the words of Thomas Nagel, that 'actions are events and people things. ${ }^{, 27}$

\footnotetext{
${ }^{26}$ Slote (2001), p. 39.

${ }^{27}$ Nagel, Moral luck, in Mortal Questions (Cambridge: Cambridge University Press, 1979), p. 37.
} 